\title{
AVALIAÇÕES SUBJETIVAS E RELACIONAIS: O EQUÍVOCO DO SISTEMA AVALIATIVO DOCENTE PARA A QUALIDADE DOS CURSOS DE PÓS-GRADUAĈ̃O MBA
}

\author{
http://dx.doi.org/10.5902/2318133839416
}

\author{
Luís Henrique Rigato Vasconcellos ${ }^{1}$ \\ Flávia Fernandes Brites ${ }^{2}$ \\ Cristina Helena Pinto de Mello 3
}

\begin{abstract}
Resumo
Este trabalho teve por objetivo analisar, sob a ótica da coordenação de curso, como e porque as avaliações docentes realizadas pelos alunos ao final das disciplinas ministradas podem auxiliar o gestor a melhorar a qualidade dos cursos de pós-graduação lato sensu em Administração de Empresas denominados MBAs. Numa abordagem qualitativa, foi conduzido um estudo de caso em que foram realizadas entrevistas individuais em profundidade com os coordenadores dos programas que envolvem mais de 6.000 alunos e 500 professores da cidade de São Paulo. A análise de conteúdo das entrevistas com os coordenadores mostrou que o sistema avaliativo, atualmente praticado pela instituição de ensino do caso estudado, está mais associado a uma tentativa de mensuração de aspectos relacionais e comportamentais entre aluno-professor do que a aspectos de melhoria de qualidade dos programas ou aos seus objetivos de aprendizagem. Não ficou evidente a relação da realização das avaliações docentes com uma lógica de melhoria permanente de qualidade. Como saída adicional da pesquisa foram identificados os principais componentes que poderiam constar num sistema de avaliação que tivesse foco num programa contínuo de melhoria de qualidade.

Palavras-chave: MBA; educação executiva; avaliação docente; qualidade.
\end{abstract}

\section{SUBJECTIVE AND RELATIONAL EVALUATIONS: THE MISTAKE OF THE TEACHING ASSESSMENT SYSTEM FOR THE QUALITY OF POST GRADUATION MBA COURSES}

\begin{abstract}
The purpose of this paper was to analyze, from the point of view of the coordination of the programs, how and why the professors evaluations carried out by the students at the end of the courses taught can influence the quality of the lato sensu postgraduate courses in business administration called MBAs. In a qualitative approach, a case study was conducted where individual in-depth interviews were conducted with program coordinators involving more than 6,000 students and 500 teachers within the city of São Paulo. The content analysis of the interviews with the coordinators showed that the evaluation system, currently practiced by the teaching institution of the case studied, is much more associated to an attempt to measure relational and behavioral aspects between student-teacher than to aspects of improvement of quality of the programs or their learning objectives. It was not evident the relation of the accomplishment of the teacher
\end{abstract}

\footnotetext{
${ }^{1}$ Fundação Getúlio Vargas, Brasil. E-mail: luis.vasconcellos@gmail.com.

2 Fundação Getúlio Vargas, Brasil. E-mail: flavia.brites@fgv.br.

3 Escola Superior de Propaganda e Marketing, Brasil. E-mail: chmello@espm.br.

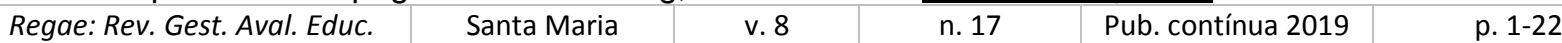


evaluations with a logic of permanent improvement of quality. As an additional output of the research, the main components that could be included in an evaluation system that really focused on a continuous quality improvement program were identified.

Key- words: MBA; executive education; teacher evaluation; quality.

\section{Introdução}

1 questão de avaliação do desempenho dos cursos de pós-graduação lato sensu na área de Administração ministrados por escolas de negócios pode ser compreendida como o conjunto das ações, práticas e meios empregados pela coordenação para tentar aferir o desempenho, tanto de docentes, quanto das iniciativas pedagógicas, a fim de alcançar os objetivos educacionais esperados de um curso e a aprendizagem dos estudantes.

Pesquisadores em educação executiva dedicaram atenção considerável ao desenvolvimento e ao teste de modelos de avaliação do desempenho docente (Silva; Gomes, 2018; Boff, 2017; Giuliani et. al, 2007). Este também é um problema relevante para as entidades certificadoras e faz parte dos modelos de acreditação dos cursos (Aacsb, 2018; Amba, 2018).

Pesquisas anteriores abordaram vários aspectos de avaliação de desempenho para cursos de educação executiva sob a ótica do desempenho docente (Boff, 2017; Shiroma; Schneider, 2014); infraestrutura da instituição (Mazaro, 2014); qualificação do corpo docente (Marquesin; Penteado; Batista (2008); avaliação por pares (Domingues; Amaral; Zeferino, 2007). Notadamente há o foco na avaliação do desempenho do docente segundo a percepção do estudante sobre tal desempenho (Maccari, 2008).

Vale ressaltar também que as instituições de ensino superior têm papel fundamental na sociedade, não só por formar os profissionais, mas também pelo desenvolvimento cultural, tecnológico, científico que a pesquisa acadêmica proporciona para a comunidade (Fonseca; Fonseca, 2016; Balbachevski, 2015; Ferreira, 2005).

$\mathrm{Na}$ última década, segundo o Instituto Nacional de Estudos e Pesquisas Educacionais (2018), os cursos de educação superior cresceram cerca de 102,6\% no Brasil. Para se manter no mercado competitivo e reter seus alunos uma IES pode precisar monitorar o nível de satisfação dos seus alunos, enfatizar a qualidade de seu ensino, bem como da experiência profissional e acadêmica de seus professores (Mazaro,2014; Eberle, 2009).

De acordo com Eberle (2009), ao se analisar especificamente os cursos de pósgraduação lato sensu, as IES precisam implantar processos de melhoria contínua com base nos objetivos da instituição. As percepções de qualidade podem incentivar a retenção de egressos, bem como a atração de novos alunos num cenário de extrema competitividade.

De acordo com o e-MEC (2018), há um número significativo de IES oferecendo cursos de especialização lato sensu e a cada dia novas instituições abrem mais cursos, aumentando a oferta deste tipo de produto e disputando preço. Neste sentido, o que se poderia discutir é se a qualidade tem gerado a mesma preocupação. 
É oportuno apontar que enquanto os cursos de pós-graduação stricto sensu são regulamentados e seguem os procedimentos estruturados de avaliação controlados pela Capes, e que podem garantir um certo padrão de qualidade e um aspecto comparativo direto entre instituições com as notas atribuídas aos seus programas de mestrado ou doutorado, os cursos de MBA lato sensu oferecidos por muitas IES não tem o mesmo rigor avaliativo. Não há um órgão ou um agente regulador que analise em profundidade a qualidade desses cursos. Muitas vezes eles apresentam baixo rigor acadêmico e poucos processos estruturados de avaliação (Balbachevski, 2015; Rego e Mucci Júnior, 2005).

Assim, um amplo sistema de avaliação, incluindo nesse rol as avaliações docentes, pode fornecer informações importantes para adequação de seus serviços, desenvolvendo seu processo de melhoria contínua e possibilitando o aumento da qualidade percebida pelos estudantes (Coutinho, 2007).

Todavia, parece haver uma questão em aberto acerca das avaliações praticadas pelas pós-graduações lato sensu que centram seus processos nos docentes e que são praticadas em muitas IES brasileiras: será que elas têm alguma relação com a melhoria de qualidade dos cursos? Elas são empregadas pelas coordenações como um instrumento de controle e melhoria de qualidade dos programas?

Neste artigo objetiva-se abordar essas questões, isto é, buscar uma melhor compreensão sobre como a avaliação docente é percebida pela coordenação acadêmica dos cursos de pós-graduação lato sensu, como instrumento de melhoria de qualidade destes cursos, analisando se as avaliações realizadas ao final de cada disciplina pelos alunos, podem auxiliá-los na melhoria da qualidade dos programas.

\section{A educação executiva e mercantilização do MBA}

Com a flexibilização de normas para concepção de cursos de nível superior, depois de 1980, a oferta desses cursos cresceu em grandes proporções no país. O curso de pósgraduação lato sensu na área de negócios, no Brasil conhecido como Master in Business Administration - MBA - é um curso que visa a promover o aperfeiçoamento profissional de seus participantes, sem o propósito de contribuir com as pesquisas ou o avanço de conhecimento nas áreas em que são oferecidos (Ikeda; Campomar; Oliveira, 2005).

Embora a sigla MBA se refira especificamente aos cursos na área de negócios, no Brasil, os cursos de pós-graduação lato sensu, com essa denominação, são destinados também para a educação continuada de executivos, como complementação da sua área de formação ou atuação e são oferecidos em diversas áreas como, por exemplo, gerenciamento de projetos, comércio exterior ou gestão de processos.

Diferente do MBA criado em Harvard, introduzido no Brasil pela Coppead/UFRJ e oferecido posteriormente por outras tantas instituições, o curso de especialização lato sensu não confere ao aluno título de mestre, tornando confusa a adoção desta nomenclatura para o oferecimento deste tipo programa.

Assim, cumpre-se esclarecer a diferença entre cursos de pós-graduação lato sensu e os cursos strictu sensu. Os cursos de pós-graduação lato sensu, de especialização ou aperfeiçoamento são cursos com duração mínima de 360 horas, voltados para a formação técnico profissional do aluno, sua formação gerencial e executiva e, ao final, o aluno 
receberá um certificado. Já os cursos de pós-graduação stricto sensu são cursos com, aproximadamente, 1.200 horas, ligados à formação científica e acadêmica, voltados para a pesquisa e o aluno receberá ao final um diploma de nível de mestrado ou doutorado.

Com o intuito de regulamentar os cursos de pós-graduação lato sensu, o Conselho Nacional de Educação, ao longo dos últimos aos, publicou as seguintes resoluções:

a) resolução n. 1, de 3 de abril de 2001: que estabeleceu normas para o funcionamento de cursos de pós-graduação;

b) resolução n. 1, de 8 de junho de 2007: que estabeleceu normas para o funcionamento de cursos de pós-graduação lato sensu, em nível de especialização;

c) resolução n. 2, de 12 de fevereiro de 2014: que instituiu o cadastro nacional de oferta de cursos de pós-graduação lato sensu das instituições credenciadas no Sistema Federal de Ensino, regulamentando que as ofertas não inscritas no cadastro nacional são consideradas irregulares; $\mathrm{e}$

d) resolução n. 1, de 6 de abril de 2018: que estabeleceu diretrizes e normas para a oferta dos cursos de pós-graduação lato sensu denominados cursos de especialização, no âmbito do Sistema Federal de Educação Superior, conforme prevê o art. 39, § 3ำ da lei n. 9.394/1996 e dá outras providências, tais como: cursos oferecidos por instituições de ensino devidamente credenciadas para oferta de cursos de graduação reconhecidos; os cursos serão registrados no Censo da Educação Superior e no Cadastro de Instituições e Cursos do Sistema e-MEC; cada curso deve prever um projeto pedagógico de curso com: matriz curricular com carga horária mínima de 360 horas, disciplinas, plano de curso, programa, metodologias de ensino, trabalhos discentes, avaliação; corpo docente e processo de avaliação de aprendizagem; corpo docente composto por, no mínimo, 30\% de portadores de título de pós-graduação stricto sensu.

Estas resoluções foram sendo introduzidas ao longo do tempo com a intenção de regulamentar os cursos de pós-graduação lato sensu, de forma a garantir certo controle sobre os cursos que estão sendo oferecidos, uma vez que o número de instituições que oferecem esse tipo de programa vem aumentando gradativamente. Segundo dados apontados pelo e-MEC (nov. 2018), existem hoje 7.124 cursos ativos de MBA na área de Ciências Sociais, Negócios e Direito. Em2017 eram 6.439 cursos ativos, na mesma área.

Desta forma, analisando o aumento dos cursos a área educacional se reformulou, tornando a competitividade entre as IES maior, especialmente as de natureza privada, possibilitando, ainda, o surgimento de empresas de consultoria especializadas nesta área, responsáveis por estudos de viabilidade e alocação de recursos (Vergara; Amaral, 2010).

Ainda corroborando com as autoras acima mencionadas, a qualidade educacional aliada a princípios mercadológicos de produtividade e rentabilidade, fez surgir a livre concorrência entre as IES e estas precisam destacar suas qualidades afim de garantir vantagens competitivas (Boff, 2017).

No entanto, para que as IES se tornem competitivas diante da concorrência, precisam também capacitar sua equipe administrativa, uma vez que os alunos podem também priorizar o relacionamento que tem com a instituição, não só se importando com o renome dela (Rizzo, 2009). 
Ainda de acordo com a autora acima, outro fator de importância é atualizar seu corpo docente, para utilização de novas metodologias e tecnologias em sala de aula, visto que muitos alunos tendem a não valorizar mais apenas 0 antigo modelo de sentar $e$ receber as informações, eles querem ter a experiência, principalmente se considerarmos os cursos de formação executiva, onde a vivência em sala de aula é importante para o desenvolvimento dos temas abordados (Rizzo, 2009).

Portanto, cabe as IES desenvolverem o relacionamento com os alunos e, de forma estratégica, identificar e compreender a qualidade percebida pelos alunos, com o intuito de assegurar sua sobrevivência no mercado (Ikeda, Campomar e Oliveira, 2005; Rizzo, 2009).

\section{$\mathrm{O}$ aluno/cliente?}

Historicamente a relação estabelecida entre aluno e IES ocorre em sala de aula, onde será transmitido o conhecimento ao aluno pelo professor, sendo que este tem como função principal motivar o aluno na aprendizagem, ajudando-o nas dificuldades e facilitando o pensamento reflexivo (Vergara; Amaral, 2010). Esta relação é a prestação de serviço efetivamente adquirida pelo discente.

No entanto, é importante que o aluno também assuma seu papel nesse contrato, não só exigindo seus direitos, mas adotando a postura de coparticipante do processo educativo, uma vez que não cabe apenas ao professor the transmitir conhecimento. A principal questão que é o termo 'cliente' remete ao direito do consumidor, pressupondo-se que $o$ aluno se matricula numa instituição para receber um produto ou comprar um serviço. Nessa lógica, a compreensão da relação clientelista que pode ser assumida entre instituição e estudante é parcialmente justificada, embora reconheça-se a complexidade adicional da entrega do suposto serviço pelo docente e de sua natureza bastante diversa e controvertida (Lima; Pereira; Vieira, 2006; Fonseca; Fonseca, 2010).

Nesta situação controversa em que se discute se o aluno é cliente ou não, cabe reforçar que as obrigações de cada uma das partes envolvidas nesse contrato estão explícitas e as obrigações do aluno, embora estejam descritas em seu contrato de prestação de serviço, vão além disso, ele precisa seguir as regras e normas da instituição.

Assim, o aluno só atingirá o objetivo contratado se estiver envolvido com todo o processo de aprendizagem, fazendo parte da sua construção. É esse envolvimento que difere $o$ aluno e um cliente como os outros, uma vez que não se pode falar em qualidade se 0 aluno não estiver empenhado na construção de seu conhecimento (Carlos; Maia; 2011). É importante esclarecer as principais diferenças entre clientes e alunos apontadas por esses autores: clientes adquirem bens e serviços livremente; pagam com seus próprios recursos os bens ou serviços adquiridos; não são submetidos a avaliações para exercer seu direito; a relação entre fornecedor e cliente é impessoal; a relação termina com a entrega do produto ou serviço. Os alunos adquirem bens ou serviços mediante admissão, conforme regulamento do curso; o pagamento feito pelo aluno ou terceiros; são submetidos à avaliação, normas e regulamentos; se reprovados devem refazer o curso ou disciplina para prosseguir no curso; são corresponsáveis pelos resultados obtidos.

Assim, outras autoras como Vergara e Amaral (2011) defendem também que aluno não é cliente, pois a partir do momento que participam do processo de aprendizagem, também contribuem para a melhoria da qualidade dos serviços prestados pela instituição. 
Defendem, ainda, que o conceito de aluno como cliente deve ser revisto, uma vez que os verdadeiros clientes são a sociedade em geral, que demanda por profissionais que se comprometam com os propósitos de uma comunidade em constante transformação.

O fato de se assumir o aluno como 'não cliente' no sentido stricto (Lima; Pereira; Vieira, 2006; Vergara; Amaral; 2011; Carlos; Maia, 2011; Fonseca; Fonseca, 2016), pode ainda tornar a discussão sobre a avaliação docente realizada sob o seu ponto de vista ainda mais central na comunidade acadêmica. Como e porque algumas IES insistem em tratar as percepções dos alunos como importantes insights de seu processo decisório como se eles estivessem em plenas condições de fazê-las dentro de uma lógica supostamente clientelista? Será que quem recebe as avaliações docentes realmente as utilizam como instrumento gerencial que contribuam para a qualidade dos programas? Estas questões foram endereçadas na pesquisa descrita a seguir.

\section{0 método da pesquisa}

Para a condução deste trabalho optou-se pela utilização da pesquisa qualitativa e exploratória, não tendo a preocupação de generalizar qualquer conclusão. Como abordagem metodológica foi utilizada o estudo de caso. Entende-se nesse trabalho, um estudo de caso uma investigação empírica que examina acontecimentos contemporâneos, dentro do seu contexto da vida real, e é utilizado em situações que incluem estudos organizacionais e gerenciais, para responder questões do tipo como? e porquê? (Yin, 2015).

O motivo da opção dos pesquisadores pelo estudo de caso foi a aderência desse método as questões inicialmente propostas de pesquisa, isto é, como a avaliação docente é percebida pela coordenação acadêmica dos cursos de pós-graduação lato sensu, como instrumento de melhoria de qualidade destes cursos? Elas são utilizadas para essa finalidade? Por que?

\section{O caso estudado: a instituição de ensino escolhida}

O estudo está direcionado aos cursos executivos oferecidos por uma tradicional instituição de ensino na cidade de São Paulo, que em 2018 atendeu 7.587 alunos, sendo 5.868 alunos de cursos de MBA e pós-graduação e 1.719 alunos de cursos de extensão.

A escolha por essa instituição ocorreu por conveniência dos pesquisadores. Dois dos três autores desse artigo trabalham na instituição há mais de dez anos e percebiam que a questão da avaliação docente merecia um estudo mais aprofundado para fundamentar as decisões da direção da instituição. Em meio as discussões internas da direção da instituição havia muita especulação sobre a real percepção dos coordenadores do programa e 0 instrumento de avaliação docente, residindo nesse fato uma oportunidade ímpar de uma pesquisa que endereçasse esse tema.

O modelo praticado de avaliação docente atual constitui a unidade de análise do caso. Ela é realizada pela instituição no último dia de aula de cada disciplina, em papel, após a realização da aula. É um questionário constituído de quatro partes: auto-avaliação; conteúdo programático, material didático e professor. Os estudantes avaliam numa escala de Likert variando de 1 a 5 suas percepções em relação a esses temas. Na figura 1 apresenta-se um esquema da avaliação docente. 
Figura 1 -

Modelo de avaliação docente.

Nome do(a) Aluno(a) (opcional)

Nesse momento do curso precisamos saber como as disciplinas são avaliadas por você. Você não será identificado, por isso tenha total liberdade

para dar suas respostas. Para as próximas questões, utilize a seguinte escala:

NA: Não se aplica; 1: discordo totalmente; 2: discordo; 3 nem concordo nem discordo; 4: concordo; 5: concordo totalmente

1. Auto Avaliação

1.1 Participei ativamente da disciplina, cumprindo as exigências acadêmicas

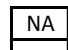

2. Coonteúdo Programático

2.10 conteúdo é relevante para minha formação

2.20 conteúdo é de fácil entendimento

2.30 conteúdo está adequado à carga horária destinada à disciplina

2.40 conteúdo é abordado de maneira prática

3. Material Didático

3.1 Os materiais escritos foram apresentados com diagramação adequada e correção gramatical

3.2 Os materiais escritos contribuiram para a aprendizagem

3.3 Os materiais audiovisuais apresentados demonstram qualidade técnica

3.4 Os materiais audiovisuais contribuiram para a aprendizagem

3.5 Os materiais didáticos foram disponibilizados até o início da disciplina

3.6 Os materiais didáticos foram facilmente acessados

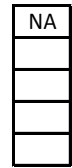

4. Professor

4.10 professor apresentou o contaúdo com clareza e segurança

4.20 professor promoveu a articulação entre a teoria e a prática

4.30 professor estimulou a interação da turma de maneira reflexiva

4.40 professor manteve postura ética, empática e acessivel durante as aulas

4.50 professor respondeu pontual e assiduamente às dúvidas que surgiram

4.60 professor orientou à realização das atividades propostas na disciplina

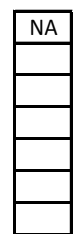

Caso possua algum comentário, escreva abaixo
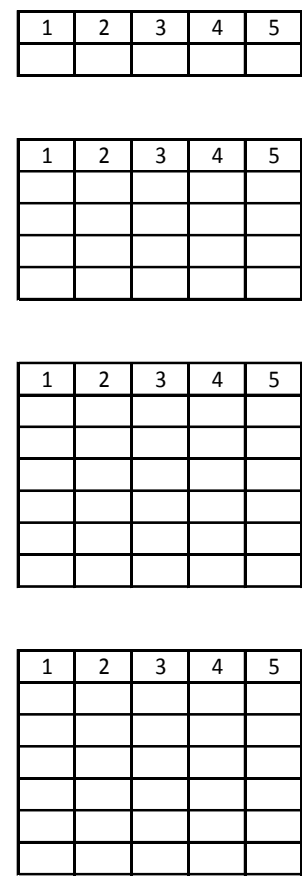

Fonte: material interno da instituição estudada.

Para a coleta de dados foi empregada a técnica de entrevistas individuais estruturadas em profundidade, resumidas por Vieira e Tibola (2005) e revisitada por Zappellini e Feurschutte (2015) como possível técnica em que as respostas podem ter autenticidade, ser flexível e possibilitar possíveis alterações no decorrer do processo investigativo.

As entrevistas individuais obedeceram a agendas determinadas de acordo com a disponibilidade dos entrevistados e ocorreram entre 21 de dezembro de 2018 e 23 de janeiro de 2019. 
O critério utilizado para escolha dos entrevistados foi o grau de conhecimento a respeito das avaliações docentes da instituição, a sua experiência acadêmica e a sua vivência em outras instituições de ensino. Desta forma, a amostra foi composta de quatro entrevistados. São todos coordenadores de MBA e também atuam como professores em seus programas.

Quadro 1 -

Perfil dos respondentes.

\begin{tabular}{|c|l|l|c|c|c|c|}
\hline Sigla & \multicolumn{1}{|c|}{ Respondente } & Formação & $\begin{array}{c}\text { Turmas } \\
\text { ativas }\end{array}$ & $\begin{array}{c}\text { Alunos } \\
\text { ativos }\end{array}$ & Professores & $\begin{array}{c}\text { Duração da } \\
\text { Entrevista }\end{array}$ \\
\hline R1 & $\begin{array}{l}\text { Coordenador dos } \\
\text { cursos: Gerenciamento } \\
\text { de Projetos e } \\
\text { Desenvolvimento } \\
\text { Humano de Gestores }\end{array}$ & Doutorado & 70 & 2.197 & 185 & 46 minutos \\
\hline $\begin{array}{l}\text { Coordenadora dos } \\
\text { cursos: Recursos } \\
\text { Humanos e } \\
\text { Desenvolvimento } \\
\text { Humano de Gestores }\end{array}$ & Mestrado & 35 & 870 & 95 & 34 minutos \\
\hline R3 & $\begin{array}{l}\text { Coordenador dos cursos } \\
\text { de Finanças e Gestão } \\
\text { Empresarial }\end{array}$ & Doutorado & 133 & 1.701 & 200 & 19 minutos \\
\hline R4 & $\begin{array}{l}\text { Coordenador dos cursos } \\
\text { de Gestão Empresarial } \\
\text { e Comércio Exterior }\end{array}$ & Doutorado & 70 & 1.958 & 170 & 60 minutos \\
\hline Total & \begin{tabular}{l} 
- \\
\hline
\end{tabular} & - & 308 & 6726 & 650 & 159 minutos \\
\hline
\end{tabular}

Fonte: dados da pesquisa.

Apenas um deles está em fase de conclusão do doutorado, os demais já o concluíram. Os respondentes lecionam na instituição há mais de 10 anos e são coordenadores participativos de suas turmas, visitando-as sempre, mantendo contato com os representantes de sala e atuando junto com a área administrativa da IES sempre que solicitado.

O roteiro de entrevistas serviu como um direcionamento para as entrevistas, cabendo ao pesquisador incluir ou retirar perguntas que considerar pertinentes para aprofundamento do tema de acordo com o conhecimento de cada entrevistado (Vieira; Tibola, 2005). Para a condução da pesquisa foi elaborado um questionário contendo 16 perguntas exploratórias, com o objetivo de sistematizar o conhecimento dos respondentes a respeito do assunto abordado.

O instrumento de pesquisa foi elaborado com base no atual processo avaliativo da IES, considerando o modelo praticado e com o objetivo de estudar a percepção dos entrevistados a respeito da avaliação docente e análise da aceitação de novos instrumentos de avaliação, com base em novas metodologias e formatos de avaliação.

No quadro 2 é apresentada uma síntese das questões utilizadas nas entrevistas estruturadas, respectivos objetivos esperados, sendo que todos os entrevistados responderam as mesmas questões. 
Quadro 2 -

Questões para entrevistas e objetivo de cada pergunta.

\begin{tabular}{|c|c|c|}
\hline & Questões & Objetivos \\
\hline 1 & $\begin{array}{l}\text { Qual seu nome, sua formação e os cursos } \\
\text { que coordena na instituição? }\end{array}$ & Conhecer o respondente \\
\hline 2 & $\begin{array}{l}\text { De que forma o curso sob sua coordenação } \\
\text { é avaliado pelos alunos? }\end{array}$ & $\begin{array}{l}\text { Compreender a de forma ampla como é o processo } \\
\text { de avaliação }\end{array}$ \\
\hline 3 & $\begin{array}{l}\text { Você recebe o resultado das avaliações } \\
\text { docentes das suas turmas? Quando? E de } \\
\text { que forma? }\end{array}$ & $\begin{array}{l}\text { Entender em que momento os coordenadores } \\
\text { recebem as informações sobre suas turmas, nas } \\
\text { diversas escolas da instituição }\end{array}$ \\
\hline 4 & Como você define a avaliação docente? & $\begin{array}{l}\text { Identificar o ponto de vista de cada um a respeito da } \\
\text { avaliação docente }\end{array}$ \\
\hline 5 & $\begin{array}{l}\text { Qual a importância desta avaliação e por } \\
\text { que? }\end{array}$ & Identificar a importância da avaliação docente \\
\hline 6 & $\begin{array}{l}\text { Qual a sua percepção sobre o processo de } \\
\text { avaliação docente feita pela instituição } \\
\text { como um todo? Por que? }\end{array}$ & $\begin{array}{l}\text { Estabelecer o entendimento de cada um em relação } \\
\text { a avaliação feita em cada curso }\end{array}$ \\
\hline 7 & $\begin{array}{l}\text { Na sua percepção, os critérios aplicados na } \\
\text { avaliação docente atual são válidos? Por } \\
\text { que? }\end{array}$ & $\begin{array}{l}\text { Identificar o conhecimento de critérios ou métodos } \\
\text { de avaliação docente que poderiam ser adotados } \\
\text { pela instituição }\end{array}$ \\
\hline 8 & $\begin{array}{l}\text { De que forma você percebe que a avaliação } \\
\text { docente atualmente praticada no seu curso } \\
\text { pode auxiliar no desenvolvimento da } \\
\text { capacidade profissional e científica do } \\
\text { professor? }\end{array}$ & $\begin{array}{l}\text { Identificar utilização de informações da avaliação } \\
\text { como indicador de qualidade }\end{array}$ \\
\hline 9 & $\begin{array}{l}\text { De que forma a avaliação docente } \\
\text { atualmente praticada no curso sob sua } \\
\text { coordenação é utilizada como ferramenta } \\
\text { de gestão de qualidade? Cite exemplos }\end{array}$ & $\begin{array}{l}\text { Identificar até que ponto as avaliações docentes são } \\
\text { utilizadas como parâmetro para revisão dos } \\
\text { programas oferecidos }\end{array}$ \\
\hline 10 & $\begin{array}{l}\text { Qual a periodicidade em que é aplicada a } \\
\text { avaliação docente nos seus cursos? }\end{array}$ & Verificar se há "fadiga de pesquisa" \\
\hline 11 & $\begin{array}{l}\text { Qual a periodicidade que considera } \\
\text { adequada? }\end{array}$ & $\begin{array}{l}\text { Estabelecer se há necessidade de propor uma nova } \\
\text { periodicidade }\end{array}$ \\
\hline 12 & Qual o formato da avaliação? & Verificar como se aplica \\
\hline 13 & Qual formato considera o adequado? & $\begin{array}{l}\text { Estabelecer se há necessidade de propor um novo } \\
\text { formato }\end{array}$ \\
\hline 14 & $\begin{array}{l}\text { Como a avaliação docente atualmente } \\
\text { praticada é relacionada como os objetivos } \\
\text { de aprendizagem do curso sob a sua } \\
\text { coordenação? }\end{array}$ & $\begin{array}{l}\text { Estabelecer se há necessidade de propor um novo } \\
\text { formato }\end{array}$ \\
\hline 15 & $\begin{array}{l}\text { Considera que a avaliação docente } \\
\text { atualmente praticada no curso é útil para a } \\
\text { melhoria de qualidade de seu programa? } \\
\text { Como e Por que? }\end{array}$ & $\begin{array}{l}\text { Estabelecer se há necessidade de propor um novo } \\
\text { formato }\end{array}$ \\
\hline 16 & Algo que gostaria de acrescentar? & Encerramento \\
\hline
\end{tabular}

Fonte: dados da pesquisa. 
É importante apontar que durante a fase da pré-análise dos dados optou-se por criar uma nuvem de palavras com o software gratuito Wordclouds com as manifestações dos coordenadores entrevistados, para se obter os primeiros insights. Também foram analisadas as tabelas quantitativas de freqüências geradas pelo software, tanto para cada entrevistado, quanto para a totalidade. As nuvens de palavras e as tabelas quantitativas possibilitaram levantar algumas suposições para o momento da análise de conteúdo e das apresentações das unidades de registro.

Após a transcrição das entrevistas e a visualização da nuvem de palavras foi realizada a análise de conteúdo. Compreende-se nesse artigo a análise de conteúdo como uma técnica de avaliação das comunicações dos entrevistados, que investiga o que foi dito nas entrevistas ou observado pelos pesquisadores. Nessa análise, buscou-se agrupar as similaridades dos discursos das entrevistas em temas ou categorias que auxiliassem na compreensão do que estava por trás das falas dos coordenadores (Silva; Fossá, 2015).

É oportuno apontar que foram seguidas as recomendações propostas por Bardin (2011), para a análise de conteúdo e formação das categorias de análise, a saber: 1) leitura geral do material coletado: entrevistas e documentos; 2) codificação para formulação de categorias de análise, utilizando o quadro referencial teórico e as indicações trazidas pela leitura geral; 3) recorte do material em unidades de registro: palavras, frases e parágrafos comparáveis e com o mesmo conteúdo semântico; 4) estabelecimento de categorias que se diferenciam, tematicamente, nas unidades de registro: passagem de dados brutos para dados organizados; 5) agrupamento das unidades de registro em categorias comuns; 6 ) agrupamento progressivo das categorias: iniciais intermediárias e finais; 7) inferência e interpretação, respaldadas no referencial teórico.

Para análise dos dados foram criadas seis categorias de análise isto é: importância da avaliação docente; percepções sobre o processo de avaliação; validade dos critérios atuais; possibilidade da avaliação auxiliar no desenvolvimento docente e relação da avaliação como os objetivos de aprendizagem (Bardin, 2011).

No quadro 3 apresenta-se o resumo das seis categorias de análise que serão detalhadas no decorrer do trabalho.

Quadro 3 -

Categorias de análise.

\begin{tabular}{|c|c|c|c|}
\hline \multicolumn{4}{|c|}{ Matriz de análise das categorias } \\
\hline \multicolumn{2}{|r|}{ Categorias de análise } & Resumo das respostas & Respondente \\
\hline 1 & Importância da Avaliação Docente & Alta & $\mathrm{R} 1, \mathrm{R} 2, \mathrm{R} 3$ e $\mathrm{R} 4$ \\
\hline \multirow{4}{*}{2} & \multirow{4}{*}{$\begin{array}{l}\text { Percepções sobre o processo de } \\
\text { avaliação }\end{array}$} & Tem alguma utilidade & $\mathrm{R} 1$ \\
\hline & & Equivocado & $\mathrm{R} 2$ \\
\hline & & Muito fraco & R3 \\
\hline & & Equivocado & R4 \\
\hline \multirow{3}{*}{3} & \multirow{3}{*}{$\begin{array}{l}\text { Validade dos Critérios Atuais de } \\
\text { Avaliação }\end{array}$} & No geral, são. Mas são o único & $\mathrm{R} 1$ \\
\hline & & Não, porque é muito subjetivo & $\mathrm{R} 2$ \\
\hline & & São válidos, mas são fracos & R3 \\
\hline
\end{tabular}




\begin{tabular}{|c|c|c|c|}
\hline & & Não são válidos em todos os aspectos & R4 \\
\hline \multirow{4}{*}{4} & \multirow{4}{*}{$\begin{array}{l}\text { Possibilidade da Avaliação auxiliar } \\
\text { no desenvolvimento da capacidade } \\
\text { profissional e científica do professor }\end{array}$} & Não & $\mathrm{R} 1$ \\
\hline & & $\begin{array}{l}\text { Se considerarmos que o relacionamento } \\
\text { aluno/professor é uma competência a ser } \\
\text { desenvolvida, ajuda. Mas só nisso }\end{array}$ & $\mathrm{R} 2$ \\
\hline & & Não ajuda em absolutamente nada & R3 \\
\hline & & Às vezes ajuda & $\mathrm{R} 4$ \\
\hline \multirow{4}{*}{5} & \multirow{4}{*}{$\begin{array}{l}\text { Possibilidade da Avaliação ser } \\
\text { usada como ferramenta de gestão } \\
\text { da qualidade }\end{array}$} & Não & $\mathrm{R} 1$ \\
\hline & & Só do componente relacional & $\mathrm{R} 2$ \\
\hline & & $\begin{array}{l}\text { Muito ruim, para o meu curso contribui } \\
\text { muito pouco }\end{array}$ & R3 \\
\hline & & $\begin{array}{l}\text { Sim, quando vejo algum problema, } \\
\text { converso com o professor }\end{array}$ & R4 \\
\hline \multirow{4}{*}{6} & \multirow{4}{*}{$\begin{array}{l}\text { Relação da Avaliação Docente com } \\
\text { os objetivos de aprendizagem do } \\
\text { curso }\end{array}$} & Muito pouco & $\mathrm{R} 1$ \\
\hline & & Nada relacionado & $\mathrm{R} 2$ \\
\hline & & Quase nada & R3 \\
\hline & & Nada relacionado & $\mathrm{R} 4$ \\
\hline \multirow{4}{*}{7} & \multirow{4}{*}{$\begin{array}{l}\text { Utilidade da Avaliação Docente para } \\
\text { melhoria de qualidade do programa }\end{array}$} & Não & $\mathrm{R} 1$ \\
\hline & & Não impacta diretamente & $\mathrm{R} 2$ \\
\hline & & De alguma forma, mas muito superficial & R3 \\
\hline & & De alguma forma, superficial & R4 \\
\hline
\end{tabular}

Fonte: dados da pesquisa.

\section{Importância da avaliação docente}

$\mathrm{Na}$ percepção dos coordenadores, o processo avaliativo é importante para a instituição justamente por ter cursos oferecidos em diversas cidades brasileiras e estar levando o nome da organização a diversos estados, por meio dos contratos de convênios com outras instituições parceiras.

Embora alguns coordenadores critiquem o processo avaliativo, todos os entrevistados o consideram importante que algum tipo de avaliação seja feito e que essa avaliação não considerasse apenas o ponto de vista do aluno, mas que o professor pudesse ser avaliado por outros critérios que não se restringissem apenas aos alunos. Conforme apontado nas entrevistas e utilizadas nas unidades de registro da análise de conteúdo:

"Todo mundo tem que ser avaliado de alguma maneira. Eu acho que tem que ter alguma avaliação, sou contra os que dizem que não tem que ter avaliação, entendeu? A gente vê o pessoal dizendo que no doutorado você pode fazer o que quiser que não tem avaliação. Basicamente, o que a pessoa está dizendo: que se dane o aluno, que se dane quem tá ali. Eu acho que de alguma maneira você tem que fazer alguma avaliação. Você tem que ter alguma informação de como essa pessoa está junto aos alunos, à instituição, junto aos stakeholders, né?! Eu sou totalmente a favor da avaliação, eu só acho que ela tem que ser olhada sem ser somente pelo lado do professor, tem que ver os outros interesses e problemas." (R1) 
"Acho que é importante, porque tem a ver com gestão de desempenho da equipe e oportunidade de melhoria. É vital." (R2)

"A importância da avaliação é para a gente melhorar sempre, qualidade é uma corrida sem linha de chegada, é sempre melhorar, sempre evoluir, principalmente com um mundo que muda muito rápido. Eu vejo isso com clareza, docentes que são espetaculares hoje, 5 anos depois já não são mais tão espetaculares assim, tem uma queda, nessa história." (R3)

"Acho que a avaliação é importante, porém não pode ser encarada ou analisada friamente para decisão da escolha dos professores, outros aspectos e problemas têm que ser avaliados, outras métricas, que estão de uma certa forma relacionadas com a avaliação, mas que também não são definidos pelos alunos, por exemplo: atraso de inserção de prova, correção de prova, atraso na inserção de material, problemas éticos dos professores. Essas métricas juntamente com a avaliação é que devem ser utilizados para ter uma avaliação mais 180 graus dos professores." (R4)

\section{Percepções sobre o processo de avaliação}

Os coordenadores percebem que o processo avaliativo, embora traga algumas informações que possam ser utilizadas, é um processo equivocado, que referencia apenas o relacionamento professor/aluno:

"Equivocada, né?! A gente não foca na verdade, na qualidade da entrega propriamente dita ou na questão do que o aluno está ganhando com isso, ou o que o aluno está fazendo com esse conteúdo. Ela fica muito colocada na percepção do relacionamento professor-aluno. Acho que os critérios é que não são legais, porque, de repente, tem aluno que pode avaliar mal um professor e na verdade ele está tendo um aproveitamento daquilo no trabalho dele efetivo e tem aluno que pode estar avaliando bem e não estar fazendo nada com aquele aprendizado. Eu acho que ela não avalia o que precisa ser avaliado." (R2)

"Eu acho o processo muito fraco de avaliação docente, e eu acho muito fraco, porque a gente tem basicamente duas métricas, que é o aluno gostou ou não do docente e agora se o docente atrasou ou não a prova. Mas são critérios que eu acho fracos, muitas vezes subjetivos, na minha opinião a Fundação precisa, antes de criar um processo de avaliação, se perguntar o que que ela espera do docente, comunicar com clareza o que ela espera do docentee depois disso começar a avaliar e dar feedback para o docente." (R3)

"O processo de avaliação contínua deveria servir para que a gente pudesse municiar o docente de informação para que ele pudesse se desenvolver, obviamente que a gente tem que olhar mais sob o aspecto de desenvolvimento do docente, do que punitivo por si só. Hoje eu acho que o modelo é falho em termos de avaliar o docente e seus problemas, e é muito punitivo o modelo. A gente oferece muito pouca informação para que possa melhorar." (R4) 


\section{Validade dos critérios atuais de avaliação}

Os coordenadores apontaram que a validade dos critérios atuais de avaliação é fraca e que precisariam ser alterados para que as avaliações tivessem um caráter menos subjetivo e mais de entrega da qualidade do ensino. O discurso dos coordenadores converge em apontar o caráter dicotômico da avaliação docente em retratar o 'gostar ou não gostar' do professor, independente do conteúdo ou do rigor do processo de aprendizado.

Foi ponderado também que o relacionamento aluno/professor é importante dentro de sala de aula, mas não é o fator principal. Além disso, que a instituição tem apenas o ponto de vista do aluno e, muitas vezes, esse é uma determinante para a continuidade de um professor em um curso quando outras partes poderiam ser ouvidas e levadas em consideração e não apenas o aluno:

"No geral, eles são válidos. Eu só acho que eles são o único critério. Esse que é o problema. É igual você ter um funcionário que lida com um monte de gente, par e chefes, em uma estrutura matricial e um só avalia. De repente, esse um só que avalia, é o um que não tenha muito caráter, que de repente não gosta desse funcionário. Então, na minha opinião, é mais ou menos isso, só temos uma opinião. Ficamos na mão de uma turma, como já vi em alguns casos, de grupos de alunos que estão claramente irritados e não querem fazer o que você está pedindo como professor e te desafiam. O que você faz num momento como esse? O professor tem que ter muito tato. Falta um fechamento melhor de todo esse processo." (R1)

"Eu diria que não, porque toda a avaliação, todo o processo avaliativo, não especificamente só o da instituição, tem um viés muito subjetivo. Precisamos diminuir esse grau de subjetividade, mas algum sempre terá. Eu acho que a nossa avaliação ela estimula essa subjetividade. Ela fica uma coisa muito personalista, muito em cima do eu gosto ou eu não gosto. (R2)

"Eles são válidos, mas são fracos. Eles avaliam apenas um pedacinho da história, obviamente que escutar o aluno e saber se o aluno gostou ou não da aula é importante, mas eu acho que é feito de forma meio genérica e baseado apenas em um critério só, $100 \%$ do peso é aluno gostou ou não. Então, é uma formação extremamente subjetiva e muito fraca e não está medindo se a gente está entregando uma boa aula para o aluno. Simplesmente está medindo se o aluno gostou ou não da aula, o que é muito diferente." (R3)

"Acho que os critérios não são necessariamente válidos em todos os aspectos, porém dá uma sinalização do perfil do professor, porém não podem ser utilizadas friamente para decisão de escolha do professor. Momentos da turma, momentos em que a avaliação é passada, tipo de disciplina, perfil da turma, são diversas variáveis que acabam interferindo nessa avaliação. Que dita de uma forma ou de outra a vida de sucesso do 
professor, seja na escolha dos coordenadores, porque realmente essa é a métrica da instituição, seja até no aspecto psicológico do professor, que fica muito afetado quando é injustamente feita uma avaliação negativa por parte dele." (R4)

A crítica que se faz ao atual modelo de avaliação e a sua validade é que se trata muito de avaliar aspectos relacionais do professor com a turma e não o que realmente o aluno está aprendendo ou levando para sua vida profissional daquilo que viu em sala de aula. Ademais, é sinalizada pelos entrevistados a condição de refém que alguns professores se colocam ao se submeter exclusivamente a um sistema avaliativo centrado apenas nas percepções dos alunos:

"A avaliação docente é muito ruim, porque você fica totalmente na mão dos alunos. Ela é muito comportamental, ela é muito simpatia. Os professores percebem isso, ninguém é ingênuo. Qualquer professor novo, depois de algum tempo convivendo com os outros nas vans e aeroportos, eles começam a perceber que eles precisam ser legais com os alunos. Esse é o termo, tem que ser legal. Eu não acho que isso é ruim, eu acho que o professor tem que ser agradável, que se chegar ao aluno, mas eu acho que isso tem que ser feito de uma maneira civilizada, mas quando essa forma civilizada começa a querer virar encantamento, é que vira problema. Tivemos aquelas deformações do passado, que o diretor da escola muito crítico disso, foi um dos que bateu mais forte nisso, professor rezando em sala de aula, professor colocando imagem dos filhos ou em visitas à instituição de caridade, tinha de tudo, balinha, tinha professor que fazia buffet no último encontro com garçom para servir a turma. Então, se o professor só é avaliado pelo aluno, quer dizer, é quase que um circo romano, às vezes, as pessoas ficam muito magoadas, porque eles acham que a instituição dá muito peso a isso. Se eles não foram legais com os alunos, mesmo sentindo que eles deram uma boa aula, às vezes, temos turmas que tem muitos alunos que não querem nada e que o professor tem que arrumar uma forma simpática de não falar nada, para o aluno não ficar ofendido, porque se o aluno ficar ofendido, você que leva. Falta mesclar mais formas de avaliação, para a gente ter uma visão mais completa e não ficar tão refém do aluno. E tirar um pouco o lado comportamental da avaliação. Tem perguntas ali que não tem nenhum sentido, como: perguntar se o professor domina o assunto. Acho que tem que perguntar se o professor teve boa vontade na interação. Tem que ter o lado relacional do professor, que obviamente, o professor tem que ter alguma simpatia, isso é inevitável." (R1)

"Quando eu vejo a avaliação de docente, eu acho que ela uma ferramenta importante e necessária para gestão da qualidade da nossa entrega e para a gestão do desempenho da minha equipe, se eu entender que sou uma líder dessa equipe. Então, para mim ela é necessária. Eu entendo que a forma que ela é feita, ela está equivocada, tanto do ponto de vista do como, como do ponto de vista do critério, porque o que eu percebo hoje, que tem a ver com a Fundação, não só na avaliação de desempenho, o 
aluno está muito empoderado, ok?! Então, eu acho que ele na grande maioria, com raras exceções, ele não tem bagagem, conteúdo e, às vezes até, nem postura para avaliar e aí essa avaliação acaba sendo altamente distorcida." (R2)

"Eu acho que a avaliação nossa é muito ruim, porque ela mede no final se o aluno gostou ou não do docente e numa instituição de ensino, que a gente trabalha com um bem credencial, diferente de um produto, a gente tem dificuldade primeiro em definir muito bem o que a gente espera do docente e depois avaliar se isso que a gente espera está sendo entregue. Hoje a gente acaba avaliando se o aluno no final gostou do docente ou da aula do docente, que é muito misturado isso aí, e não se o docente entregou um bom curso." (R3)

Portanto, infere-se que tanto o questionamento dos docentes, quanto o conteúdo do questionário não contribuem para uma avaliação qualitativa na medida em que é percebido pelos docentes como instrumento de coerção e relação de poder.

\section{Possibilidade de a avaliação auxiliar no desenvolvimento da capacidade profissional e científica do professor}

No que tange à possibilidade da avaliação auxiliar no desenvolvimento da capacidade técnica e científica do professor, os coordenadores, na sua maioria, entendem que a avaliação docente atual não ajuda muito, mas a partir do momento que se considera que a competência relacional é importante para o professor em sala de aula, a avaliação passa a ser uma aliada do coordenador, para mediar os casos em que, eventualmente, o professor possa cometer algum tipo de exagero.

Além disso, há uma crítica muito grande, de forma geral, que professores que cobram mais dos alunos acabam sendo mais mal avaliados. Esse ponto ficou evidente no discurso dos entrevistados:

"Eu acho que na prática contribui muito pouco. Eu vejo que, às vezes, vem comentários consistentes de alunos em relação a parte de comportamento do professor. Isso me ajuda. Então, alguma forma como o professor agiu, alguma resposta que deu, etc. Então, nesses casos, fica tranquilo perceber que foi útil, mas no geral quando tem algum problema mais grave, eu fico sabendo pelo representante de turma. Professor que deu tudo certinho, não tira necessariamente nota tão alta. Professor tem que ter um relacionamento, isso faz diferença e os professores sabem disso. Quando dá algum problema mais sério a gente fica sabendo logo, ou a secretaria me avisa, o representante me liga. Tragédia chega rapidinho, sabe?! No geral, ela não é muito útil, não, porque nos casos mais extremos a gente fica sabendo logo por outros canais." (R1)

"Falar que nenhuma, talvez eu esteja sendo radical. Sabe por que que eu digo isso? Porque, por exemplo, quando eu leio as minhas avaliações, mesmo não concordando com elas, elas me geram um processo crítico muito grande, como professora. Então, dizer que serve para nada, eu acho radical, mas eu diria que do ponto de vista da competência profissional e 
científica, nenhuma. Agora que essa avaliação agregue valor para eu perceber de que maneira eu poderia melhorar tecnicamente falando, ou $o$ meu conteúdo o a minha abordagem mais científica, isso não ajuda. Mas se eu entendo que ser um bom professor implica também em uma dimensão comportamental relacional é claro que isso me gera uma atitude crítica e reflexiva, independente se essa reflexão vai me gerar a uma concordância e uma mudança de atitude ou não, que aí é um segundo passo. (R2)

"Hoje, na minha opinião, a avaliação não ajuda em absolutamente nada. É só burocracia e ao invés de ajudar atrapalha. A maioria dos docentes fica muito preocupada em simplesmente ter uma avaliação muito próxima de 10 e meu grande mestre diz o seguinte: se alguém está com média 10, tem alguma coisa errada, ninguém é unânime em tudo e o docente precisa aprender a falar não e quando ele fala não, eventualmente, o aluno não gosta e a gente está extremamente preocupado em dizer sim para o aluno, só se diz sim para o aluno e muitas vezes, infelizmente. A gente fica alimentando esse modelo que é muito ruim." (R3)

Falta, dessa maneira, uma intencionalidade no processo avaliativo que possa servir de instrumento objetivo para o gestor no sentido de melhorar a qualidade percebida do curso pelos discentes.

\section{Possibilidade da avaliação ser usada como ferramenta de gestão da qualidade}

A avaliação docente é pouco utilizada como ferramenta de gestão da qualidade, porque não traz subsídios para isso. Os coordenadores entendem apenas como um critério para avaliar o comportamento e o relacionamento do professor com os alunos em sala de aula e muitas vezes orientá-lo nesse sentido.

Os coordenadores mais participativos em suas turmas costumam conversar com os alunos e escutarem deles ao longo do curso, pessoalmente, em avaliações informais, o que eles pensam do programa e como os professores estão se desenvolvendo em sala de aula:

"Eu não uso como ferramenta de gestão de qualidade. Eu prefiro ouvir mais as críticas diretas dos alunos em relação ao programa, dos próprios professores. Contribui pouco. Eu vejo muito mais as possibilidades de mudança pelo que os alunos pedem, quando eu converso com eles ou quando dão as sugestões espontaneamente. Para mim, esses canais são melhores. Eu confio muito mais nisso, do que na avaliação." (R1) 
"Hoje, só do componente relacional, se a instituição quiser avaliar, tiver entendimento da qualidade do curso tem a ver com o quanto os professores são queridos pelos alunos, esse elemento resolve, mas eu diria que do ponto de vista da qualidade do curso ela não agrega valor, não." (R2)

"Para o meu curso também é muito ruim, porque ela contribui muito pouco para o crescimento do curso. A avaliação por si só, hoje em dia, contribui muito pouco, no feedback pelo qual a gente poderia ajudar os docentes a melhorar." (R3)

Os entrevistados levantam o fato de a avaliação abordar o aspecto relacional do professor, interferindo pouco em relação ao conteúdo ou qualidade do curso:

"A avaliação não me ajuda na melhoria da qualidade do programa. Eu só vejo se o professor teve problema de relacionamento com a turma, se ele atualmente deixou de dar alguma coisa que na prova ele cobrou. Eu escuto mais coisas quando vou visitar a turma, do que os alunos colocam as informações na avaliação. Para mim, os canais melhores são via representante ou nas visitas às turmas." (R1)

"Se a gente entende que relacionamento é uma competência importante nessa entrega, aí me traz algumas informações sobre quem está conseguindo estabelecer esse relacionamento legal com os alunos, e de certa forma preservar alguns aspectos que tem a ver com a instituição e as nossas diretrizes, aí dá pra perceber isso, mas é parcial." (R2)

"Avaliação sempre é importante, sempre dá feedbacks e, obviamente, com isso acaba de uma forma ou de outra melhorando a qualidade do curso, aprimorando o desempenho dos professores. Só que não pode ser tomada avaliação como o único instrumento para decisão da escolha ou manutenção de um professor, mas, obviamente, que ela é positiva no sentido de trazer algumas coisas observações, tem que ter um bom senso na leitura dessas avaliações, mas é positiva nesse aspecto." (R4)

Reconhece-se assim que embora não praticada, há a oportunidade de a avaliação docente ser uma importante ferramenta de qualidade para o curso. Contudo, ela não pode ser a única fonte de informação entre os estudantes e a coordenação. Os coordenadores percebem o superdimensionamento do aspecto relacional da avaliação e optam por outras formas de coletar informações para a qualidade, tais como visitas e conversas informais com as turmas ou com seus representantes.

\section{Relação da avaliação docente com os objetivos de aprendizagem do curso}

A avaliação docente atual não tem nenhuma relação com os objetivos de aprendizagem dos cursos de MBA oferecidos pela instituição. Isso ficou evidente nas palavras dos entrevistados: 
"Muito pouco. Para mim avalia comportamento. Como o professor interagiu, mas não avalia nada de qualidade. Como eu sei disso? Muitas vezes eu recebo uma reclamação de um aluno que o professor não deu tal assunto, aí eu vejo o material, peço ao professor o relatório, ele coloca tudo que viu, aí mando para o aluno e peço que ele comente o que não está correto e ele não consegue mostrar. Então, você olha e vê que está tudo ali. $O$ aluno mente muito." (R1)

"Nada relacionado com os objetivos de aprendizagem. Ela avalia uma única competência, que é o relacionamento professor-aluno. Ela não avalia objetivo de aprendizagem. E é aí que mora o grande problema, ela tem que estar estruturada em cima dos objetivos de aprendizagem daquela disciplina. Para isso, os professores vão precisar de ajuda, porque a grande maioria dos professores não sabe definir ou redigir objetivos de aprendizagem. E a grande maioria não vê isso naquele manual que ensina a fazer material, que naquele manual tem umas dicas da taxonomia de Bloom, etc., mas tem horas que eu reprovo material pedindo que o professor reveja pedindo que ele siga as diretrizes, porque eu não posso aceitar isso como objetivo da sua disciplina. Para a avaliação estar ligada aos objetivos, os objetivos terão que estar muito bem definidos, infelizmente a gente não tem isso hoje." (R2)

Essa categoria de análise revelou um problema estrutural para a qualidade dos cursos: a ausência de objetivos de aprendizagem mais claros na visão dos coordenadores de programa e de seus professores.

\section{Conclusões e contribuições da pesquisa para a prática}

De um modo geral, na visão das coordenações dos programas avaliados, há um entendimento que o processo avaliativo é muito importante para a instituição, e que é preferível manter o atual, mesmo que falho, a não ter nenhum. Todavia, as ponderações dos entrevistados apontam para a necessidade de redesenho da sistemática da avaliação docente empregada pela IES.

A insatisfação com o modelo atual se amplifica no fato dele avaliar de sobremaneira a questão comportamental do professor, seu relacionamento em sala de aula com o aluno e trazer poucas informações a respeito da qualidade do conteúdo ou o que de fato os alunos têm aprendido dentro e fora de sala de aula, que é um dos intuitos dos programas MBA.

Ao analisar as informações coletadas, verifica-se que a avaliação docente pouco contribui para a mensuração da qualidade dos cursos oferecidos pela instituição, por trazerem critérios baseados em aspectos relacionais subjetivos e não acadêmicos, como exposto pelos entrevistados. Desta forma, ficou claro que o atual processo avalia a competência relacional do professor e não o que o aluno está aprendendo em sala de aula efetivamente. 
Outra questão que se deve levar em consideração é o fato de que, a partir de 2018, os programas de MBA, ao serem cadastrados pela Direção Acadêmica no portal do MEC, obrigatoriamente devem apresentar o seu projeto pedagógico. Trata-se de uma situação nova para esses cursos, em que há a oportunidade de incluir de maneira mais clara os seus objetivos de aprendizagem.

Com objetivos de aprendizagem explícitos nos projetos pedagógicos, parece razoável incluir outros aspectos nas avaliações docentes além de fatores relacionais professor/aluno. Esses fatores deveriam ambicionar a mensuração desses objetivos de aprendizagem na percepção dos estudantes. Poder-se-ia, inclusive, criar formas alternativas de medição do aprendizado através de exames integrados e independentes do professor ou da disciplina.

Ainda com base nas informações coletadas nas entrevistas, outras áreas devem avaliar o docente além do aluno, incluindo suas interfaces com os serviços de apoio acadêmico. Ficou evidente na pesquisa que a avaliação monotemática a partir de percepções dos alunos sobre seus professores é um equívoco em se tratando de processos estruturados de melhoria de qualidade dos programas.

Para que o discurso de qualidade seja crível, os projetos pedagógicos dos cursos precisam criar ferramentas multidimensionais de avaliação. Devem-se incluir, assim, formas de mensurações objetivas do aprendizado dos alunos que estejam relacionados aos objetivos de aprendizagem dos cursos; medidas que levem em consideração todo o processo de aprendizagem e não apenas o momento pontual de aplicação dos questionários; e outras formas que não permitam que o docente fique num papel de refém de percepções de curto prazo dos alunos que podem passar longe do objetivo de alta qualidade dos programas.

Essa visão mais abrangente poderá contribuir para a qualidade dos programas de educação executiva e atenuará o equívoco apontado no título desse artigo em relação a forma de avaliação docente praticada no caso estudado.

\section{Referências}

AACSB. Disponível em: http://www.aacsb.edu/accreditation/accreditedmembers.asp.2018. Acesso em 10 abr. 2018.

AMBA. MBM accreditation criteria 2016. Disponível em http://www.mbaworld.com. 2016. Acesso em 2 maio 2018.

BACELLAR, Fátima Cristina Trindade; IKEDA, Ana Akemi. Objetivos e expectativas de alunos de MBA executivo. Revista de Administração da Unimep, v. 3, n. 3, 2005, p. 70-90.

BALBACHEVSKI, Elizabeth. A pós-graduação no Brasil: novos desafios para uma política bem sucedida. In: BROCK, Colin; SCHWARTZMAN, Simon. Os desafios da educação no Brasil. Rio de Janeiro: Nova Fronteira, 2005, p. 275-304.

BARDIN, Laurence. Análise de conteúdo. Lisboa: Edições 70, 2011.

BITTENCOURT, Vitor da Silva; BERNARDO, Evely Gomes. Análise dos instrumentos de mensuração da qualidade dos serviços oferecidos nas instituições de ensino superior. SINGEP, 5, 2016. Anais ... São Paulo: Singep, 2016.

BOFF, Daiane. Os programas de MBA brasileiros: uma análise sob a perspectiva de gestores. Porto Alegre: Ufrgs, 2017. 99f. Dissertação (Programa de Pós-Graduação em Administração). Universidade Federal do Rio Grande do Sul. 
CARLOS, Maria da Graça de Oliveira; MAIA, Cristhiane Pimenta. Aluno: cliente ou produto? Estudo da percepção e preferência de alunos do ensino superior em cursos da área de negócios no Ceará. ENEPQ, 1, 2011. Anais ... João Pessoa: UFPB, 2011.

COUTINHO, Fernando César Coelho. Avaliação da qualidade dos serviços de uma instituição de ensino superior. Salvador: UFBA, 2007. 123f. Dissertação (Núcleo de PósGraduação em Administração da Escola de Administração). Universidade Federal da Bahia.

EBERLE, Luciene. Identificação das dimensões da qualidade em serviços: um estudo aplicado em uma instituição de ensino superior localizada em Caxias do Sul. Caxias do Sul: UCS, 2009. 146f. Dissertação (Programa de Pós-graduação em Administração). Universidade de Caxias do Sul.

FONSECA, Marília; FONSECA, Dirce Mendes. The academic management of lato sensu graduate education: the role of the coordinator for the quality of the courses. Educação $e$ Pesquisa, São Paulo, v. 42, n. 1, 2016, p. 151-164.

GIULIANI, Antonio Carlos; NETTO, Arsênio Firmino de Novaes; PONCHIO, Mateus Canniatti; NETO, Mário Sacomano; BATISTA, Clemilson Marques. MBAs, mestrados acadêmicos, mestrados profissionais e doutorados em Administração: suas contribuições para o ensino e a pesquisa. Revista de Administração da Unimep, v. 5, n. 1, 2007, p. 5273.

IKEDA, Ana Akemi; CAMPOMAR, Marcos Cortez; OLIVEIRA, Tania Modesto Veludo. A pós-graduação em Administração no Brasil: definições e esclarecimentos. Revista Gestão e Planejamento, v. 6, n. 12, 2005, p. 1-9.

LIMA, Cássia Helena Pereira; PEREIRA, Gilberto Braga; VIEIRA, Adriane. Papéis sociais no ensino superior: aluno-cliente, professor-gerente-educador, instituição de ensinomercantil. Revista de Ciências da Administração, Florianópolis, 2006, p. 216-241.

MACCARI, Emerson Antonio. Contribuição à gestão dos programas de pós-graduação stricto sensu em Administração no Brasil com base nos sistemas de avaliação norte americano e brasileiro. São Paulo: USP, 2008. 250f. Tese (doutorado em Economia Administração e Contabilidade). Universidade de São Paulo.

MARQUESIN, Denise Filomena Bagne; PENTEADO, Adriano Franco; BAPTISTA, Denise Cristina. $O$ coordenador de curso da instituição de ensino superior: atribuições e expectativas. Revista de Educação, v. 6, n. 12, 2008, p. 7-21.

MARTINS, G.A. Avaliação do desempenho docente. In: DOMINGUES, Maria José Carvalho de Souza; SILVEIRA, Amélia (coords.). Gestão de ensino superior: temas contemporâneos. Blumenau: Furb, 2008, p. 35-49.

MAZARO, Rita Eliana. O desempenho docente no ensino superior: uma análise dos fatores de qualidade. São Paulo: USP, 2014. 174f. Tese (doutorado em Psicologia). Universidade de São Paulo.

REGO, Ingor Jean; MUCCI JÚNIOR Luis Carlos. Pós-graduação lato sensu e stricto senso: direito fundamental à educação capaz de conduzir a um relevante e renovado inovador Brasil do futuro. Revista Direitos Sociais e Políticas Públicas, v. 3, n. 1, 2015, p. 142-167.

RIZZO, Cláudia. Gestão estratégica do aluno/cliente nas instituições de ensino superior privadas: um estudo de caso. São Paulo: USP, 2009. 123f. Tese (Departamento de Administração da Faculdade de Economia, Administração e Contabilidade). Universidade de São Paulo. 
RODRIGUES; Suely da Silva. Políticas de Avaliação docente: tendências e estratégias; Ensaio: avaliação de políticas públicas, Rio de Janeiro, v. 20, n. 77, 2012, p. 749-768.

SAMPAIO, Kleber Rocha. A gestão da qualidade nas instituições de ensino superior. Faculdades Cearenses. Revista 2, v. 8, 2014, p. 20-30.

SHIROMA, Eneida Oto; SCHNEIDER, Mara Cristina. Avaliação de desempenho docente: contradições da política "para poucos" na era do "para todos". Revista Inter Ação, v. 38, n. 1, 2013, p. 89-107.

SILVA, Andressa Hennig; FOSSÁ, Maria Ivete Trevisan. Análise de conteúdo: exemplo de aplicação da técnica para análise de dados qualitativos. Qualit@s Revista Eletrônica, v. 17, n. 1, 2015, p. 1-14.

SILVA, Assis, Leão; GOMES, Alfredo Macedo. Avaliação educacional: concepções e embates teóricos. Estudos em Avaliação Educacional, São Paulo, v. 29, n. 71, 2018, p. 350-384.

SIQUEIRA, Rodrigo Pereira; CARVALHO, José Luiz Felício.Qualidade do serviço educacional prestado por escolas de Administração: confronto entre uma Universidade Pública e uma Faculdade Privada. ENCONTRO ANUAL DA ASSOCIAÇÃO NACIONAL DOS PROGRAMAS DE PÓS-GRADUAÇÃO EM ADMINISTRAÇÃO, 30, 2006. Anais ... Salvador: Anpad, 2006.

TORRES, Luciana. A mercantilização da pós-graduação lato sensu no Brasil. Curitiba: Appris, 2017.

TORRES, Rogerio Duarte. A qualidade dos serviços prestados por uma instituição de ensino superior federal na visão dos vestibulandos e universitários. Pedro Leopoldo: FCP, 2011. 96f. Dissertação (Mestrado Profissional de Administração). Fundação Pedro Leopoldo.

VERGARA, Sandra Constant; AMARAL Miriam Maia. Reflexões sobre o conceito aluno cliente de instituições de ensino superior brasileiras. ENCONTRO DA ANPAD, 34, 2010. Anais ... Rio de Janeiro: Anpad, 2010.

VIEIRA, Valter Afonso; TIBOLA, Fernando. Pesquisa qualitativa em marketing e suas variações: trilhas para pesquisas futuras. Revista da Administração Contemporânea, v. 9, n. 2, 2005, p. 9-33.

YIN, Robert K. Estudo de caso: planejamento e métodos. Porto Alegre: Bookman, 2015.

ZAPPELINNI, Marcelo Beckert; FEUERSCHUTTE, Simone Ghisi. O uso da tringulação na pesquisa científica em Administração. Administração: Ensino e Pesquisa, Rio de Janeiro, v. 16, n. 2,2015 , p. $240-273$

Luís Henrique Rigato Vasconcellos é doutor em Engenharia de Produção; professor e coordenador do Curso de Especialização em Administração de Empresas da Fundação Getúlio Vargas.

Orcid: https://orcid.org/0000-0002-4472-7258

Endereço: Avenida Nove de Julho, 2029 - 01313-902 - São Paulo - SP - Brasil.

E-mail: luis.vasconcellos@gmail.com. 
Flávia Fernandes Brites é mestre em Administração de Empresas e gerente de relacionamento dos cursos de pós-graduação do IDE da Fundação Getúlio Vargas. Orcid: https://orcid.org/0000-0003-2056-894X.

Endereço: Avenida Paulista, 548 - 01310-000 - São Paulo - SP - Brasil.

E-mail: flavia.brites@fgv.br.

Cristina Helena Pinto de Mello é doutora em Economia de Empresas pela FGV/SP e Pró-Reitora Nacional de Pesquisa e Pós Graduação Stricto Sensu da ESPM.

Orcid: https://orcid.org/0000-0002-2002-0645.

Endereço: Rua Dr. Álvaro Alvim, 123 - 04018-010 - São Paulo - SP - Brasil.

E-mail: chmello@espm.br.

Recebido em 6 de julho de 2019.

Aceito em 12 de setembro de 2019.

(c) (i) 